\title{
Dental Students' Perceptions of Effective Anatomy Teaching
}

\author{
Eiman Abdel Meguid, Ashraf Aly, William Allen \\ Queen's University Belfast, $U K$
}

\begin{abstract}
Anatomy taught courses face a unique challenge in that they are always considered a foundation course for careers in Medical / Dental and Health Sciences related fields. The increase in class size and the decrease in classroom-learning interest among students have made the teaching and learning more challenging. In recent years, many reports have shown that there is a substandard level of anatomy knowledge among medical / dental graduates). Such a deficiency definitely is having an impact on safe medical practice as there has been a steady increase in medico-legal litigation for surgical malpractice. Learner's analysis is an important step in identifying the general level of the learner characteristics. The latter include gender differences, background information and previous anatomy knowledge. This study gives guidance towards generation of teaching objectives and selection of appropriate strategies to achieve these objectives. The results of this study provide useful information in selecting effective anatomy teaching methods and generating educational strategies.
\end{abstract}

\section{Introduction}

Since the sixteenth century, formal lectures and dissection have remained a key part of any anatomy course. However, in spite of being criticized and described as outdated form of teaching, other studies found that students still prefer traditional methods such as dissection, prosection and lectures over online resources.

To ensure the effectiveness of teaching anatomy, it became necessary for the teacher not only to be aware of the changes that are taking place in higher education such as the shift from the conventional role of teacher, changes in learning styles and innovative curriculum models but also to consider the perception and learning expectations of students' prior and during the course because unfortunately student ideas are often collected and described at the end of the academic year.

Instructors should be aware that the course should achieve a distinctive, beneficial and effective teaching approach. Teachers need to understand and improve their andragogic (teaching methodology for adult learners) methods to suit the present needs. Only very few studies have attempted to describe these ideas. The literature shows a scarcity of research on anatomy programs using alternative teaching methods. Moreover, the debate continues on how to teach anatomy in the most effective way.

However, while teaching is still dominated by teacher-centered classrooms in which students passively receive information and internalize it through memorization, other important concepts such as independent learning, critical thinking and problem solving are least recognized [1].

The aim of this study was to determine whether the multimodal anatomy teaching pedagogy currently employed is perceived favorably, and which particular modalities were found to be most effective. This research critically explored the current status of different anatomy teaching pedagogical methodologies: Dissection, Prosection, Lectures, Models, Small group activity work and Online material (Dissection videos) and its effect on improving classroom / laboratory teaching from the perspectives of dental students in a UK University. This study has taken an exploratory approach to understand students' ideas about the educational value of each of the teaching approaches utilized and how these ideas could shape the student experience in an anatomy course. Consequently, it is obvious that understanding perceptions and concerns of students about methods of teaching anatomy would help academic staff to modify the existing programs to be of much higher educational strategic level. The goal was to come up with recommendations for the best teaching practice in anatomy education.

\section{Materials and Methods}

\subsection{Participants}

During the academic year 2016/2017, a total of 113 dental students (54 and 59 Students from 1st and 2nd year respectively) at School of Medicine, Dentistry and Biomedical Sciences, Queen's University Belfast, UK were invited to complete a paper-based five-point Likert-scale survey. After getting the approval of the Research Ethics Committee (University reference 16.66v2), 1st year students completed a survey about their perception on different anatomy teaching methods toward the end of the Anatomy Module while it was after its 
completion by four months with regards to 2 nd year students. The demographic breakdown of all respondents was $73.45 \%$ female and $26.54 \%$ male. In relation to their participation in the study, both anonymity and confidentiality were guaranteed. Students' background was recorded under the categories of Home/Northern Irish (NI) (65.5\%), Wider UK (13.3\%) and International students $(21.2 \%)$.

\subsection{Educational Context}

A 24-week Anatomy Module is taught during 1st year of the dental curriculum with a total of 96 hours practical sessions and 24 hours lectures. Specifically, this module covers the structure and function of the musculoskeletal, cardiovascular, respiratory, gastrointestinal, and renal in the 1 st semester and head and neck and the central nervous system in the 2nd semester.

Anatomy is traditionally delivered to dental students in the form of lectures and practical classes with prosected specimens at the beginning of the module. During the 1st few weeks of the module, students showed low engagement and low-class participation and minimal interactivity due to their diverse educational and cultural background. The need for improvement was considered. During the 2nd semester, not only did dental students dissect, examine models and prosected specimens but also their module coordinator employed interactive small group activities to promote problem solving, to activate deeper on-going retention of information and to examine post-lecture knowledge recall. During dissection, a group of eight to ten students usually share a cadaver and dissect in a rotatory manner under the supervision of a clinical demonstrator. This demonstrator in addition to explaining the steps of dissection participates in the discussion of clinical relevant information. Students were usually asked to identify anatomical structures, draw and label diagrams, examine models and solve clinical cases. During the self-directed learning, they watched online dissection videos.

\subsection{Initial Data Collection}

The primary research instrument was a structured questionnaire to collect data, conduct the investigation and assess the perception of students. The paper-based survey was a modified version of a previously validated and reliable instrument adapted from [3] for measuring student perceptions on different teaching methods. Anatomy teaching to dental students encompasses six teaching methods that were all under investigation in this study.

The questionnaire was designed to measure the educational features of a module. It was distributed among students to assess their perception about different anatomy teaching methods.

Responses to the modified survey were analysed for reliability. The internal consistency for the survey/the overall Cronbach's alpha coefficient was 0.943 which exceeds Nunnally's threshold (1978) of 0.70 , confirming that the instrument was highly reliable. With regards to individual teaching methods, it was 0.82 for dissection, 0.85 for prosection, 0.79 for lectures, 0.80 for models, 0.89 for small group work and 0.90 for dissection videos.

Part A of the questionnaire gathered respondent's demographic information on gender, attainment of previous degree and cultural background, if local, wider UK or international.

Part B mainly required students to answer by choosing one of the options using 5-point Likertscale survey ranging from "strongly disagree" to "strongly agree" by measuring subjective opinion on statements on the six anatomy teaching methods. The survey was designed in such a way as to ensure that the scale items suitably reflected the proposed domain. For the negatively framed statements, reverse mean was calculated during the analysis by using the formula: Reverse mean $=6$ - normal mean.

\subsection{Data Analysis}

Statistical analyses and interpretation of data were conducted using SPSS statistical package, version 20 (IBM Corp, Armonk, NY). Descriptive statistics including frequency, distribution, mean, and standard deviation were calculated for each statement of the survey. Kolmogorov - Smirnov test was used to examine the normality of data distribution. The negatively framed questions were accounted for before starting the analysis. Univariate analyses including Chi-Square test, Monte Carlo test and Fisher's Exact, Mann Whitney test and ANOVA test were used to perform a breakdown on demographic categorization to determine whether there were statistically significant differences in response between gender, student background, previous educational degree and previous anatomy background. A P-value was considered significant if it is $\leq 0.05$. Moreover, Post-hoc analyses were conducted using Bonferroni procedure to test for intergroup differences.

\section{Results}

113 Students completed the survey indicating a response rate of $93 \%$. Most students $(84.1 \%)$ did not have neither previous anatomy experience nor educational degree before matriculation in the dental program. Only $15.9 \%$ of them had a BSc either in Biomedical Sciences $(7.06 \%)$ or in Human Biology $(8.84 \%)$ before enrolling in this dental program. The 
latter $(8.84 \%)$ had a previous exposure to gross anatomy.

From dental students' perceptive, it was found that teaching by using prosected specimens was the best teaching method in providing a good background for other Basic Sciences Subjects and for clinical disciplines. It was also the best in appreciating anatomical variations, in helping to understand clinical anatomy and in encouraging and motivating learning. Moreover, it was found that lectures were the best in preparing for clinical skills, in helping to relate anatomical structures to pathology and in encouraging and motivating selfdirected learning. On the other hand, it was noticed that online dissection videos were the least useful (see Table 1).

Table 1. Perception of students for the usefulness of teaching methods

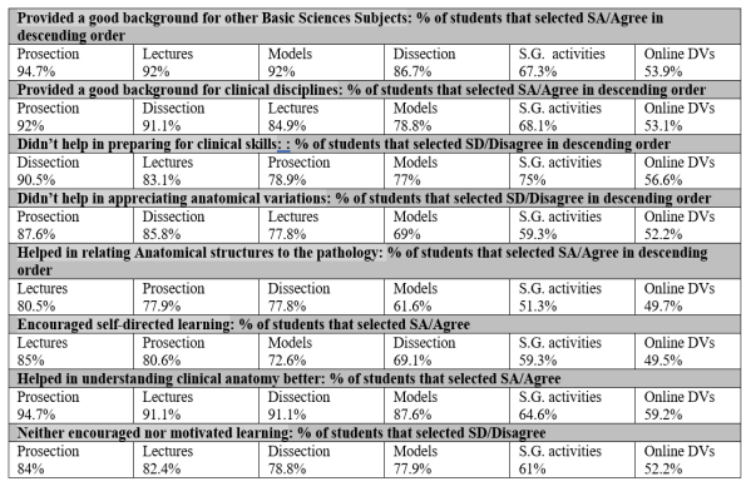

S.G.: Small group $\quad$ DVs: Dissection videos $\quad$ SA: Strongly agree $\quad$ SD: Strongly disagree

Satisfaction scores were calculated for all the six teaching methods. Students scored highly on all teaching methods used with an overall mean score $(80.4 \%)$. As a whole, prosection followed by lectures received the highest rating with a mean of $85.9 \pm 11.9$ and $84.6 \pm 10.7$ respectively. The individual score for other teaching methods was: for lectures $83.5 \pm 12.4$, for models $81.1 \pm 11.9$, for small group activity $75.2 \pm 15.5$ and for online dissection videos $72.2 \pm 15.3$. It was found that online dissection videos received the least score.

$79.6 \%$ of 1 st year students strongly agreed/agreed that dissection provided a good background for other Basic Sciences Subjects compared to about $94.4 \%$ of 2nd year students with an observed statistical significance $(\mathrm{X} 2=8.116, \mathrm{MCP}=0.039)$ between $1 \mathrm{st}$ and 2 nd year students. Similarly, $93.2 \%$ of 1 st year students strongly agreed/agreed that models were a good teaching method for the previously mentioned purpose in comparison to $91.7 \%$ of 2 nd year students. This difference was statistically significant $(\mathrm{X} 2=7.023, \mathrm{MCP}=0.029)$. Only half $(52.5 \%)$ of $1 \mathrm{st}$ year students strongly agreed/agreed that small group activities was a good teaching method for the same purpose compared to about $83.3 \%$ of the 2 nd year students. This difference was statistically significant $(\mathrm{X} 2=14.156, \mathrm{MCP}=0.002)$ (see Table2).

Table 2. Significant differences in perception of students about different teaching methods

\begin{tabular}{|c|c|c|c|c|c|c|c|c|}
\hline & & \multicolumn{2}{|c|}{$\begin{array}{l}1^{1<} \text { year } \\
(n=59)\end{array}$} & \multicolumn{2}{|c|}{$\begin{array}{l}2^{\text {sd }} \text { year } \\
(n=54)\end{array}$} & \multicolumn{2}{|c|}{$\begin{array}{l}\text { Total } \\
(\mathrm{n}=113)\end{array}$} & \multirow[t]{2}{*}{ Significance } \\
\hline & & No. & $\%$ & No. & $\%$ & No. & $\%$ & \\
\hline \multicolumn{9}{|c|}{ Teaching methods that provide a good background for other Basic Sciences Subjects } \\
\hline \multirow[t]{3}{*}{ Dissection } & SA/Agree & 47 & 79.6 & 51 & 94.4 & 98 & 86.7 & $\mathrm{X}=8.116$ \\
\hline & Neutral & 6 & 10.2 & 2 & 3.7 & 8 & 7.1 & $\mathrm{MCP}=0.039^{*}$ \\
\hline & SDDisagree & 6 & 10.2 & 1 & 1.9 & 7 & 6.2 & \\
\hline \multirow[t]{2}{*}{ Models } & SA/agree & 55 & 93.2 & 49 & 91.7 & 104 & 92.0 & $\mathrm{X}^{2}=7.023$ \\
\hline & Neutral & 4 & 6.8 & 5 & 9.3 & 9 & 8.0 & $\mathrm{MCP}=0.029^{*}$ \\
\hline \multirow[t]{3}{*}{ Small Group activities } & SA/Agree & 31 & 52.5 & 45 & 83.3 & 76 & 67.3 & \\
\hline & Neutral & 24 & 40.7 & 7 & 13.0 & 31 & 27.4 & $\mathrm{X}=14.156$ \\
\hline & SDDisagree & 4 & 6.8 & 2 & 3.7 & 6 & 5.3 & $\mathrm{MCP}=0.002^{*}$ \\
\hline \multicolumn{9}{|c|}{ Teaching methods that provide a good background for clinical disciplines } \\
\hline \multirow[t]{3}{*}{ Models } & SA/Agree & 47 & 79.6 & 42 & 77.8 & 89 & 78.8 & $\mathrm{X}=11.327$ \\
\hline & Neutral & 7 & 11.9 & 12 & 22.2 & 19 & 16.8 & $\mathrm{ACP}_{\mathrm{A}}=0.008^{*}$ \\
\hline & SD/Disagree & 5 & 8.5 & 0 & 0.0 & 5 & 4.4 & \\
\hline \multirow[t]{3}{*}{ Small Group activities } & SA/Agree & 34 & 57.6 & 43 & 79.6 & 77 & 68.1 & $\mathrm{X}=8.666$ \\
\hline & Neutral & 22 & 37.3 & 10 & 18.5 & 32 & 28.3 & $\mathrm{MCP}=0.028^{*}$ \\
\hline & SDDisagree & 3 & 5.1 & 1 & 1.9 & 4 & 3.6 & \\
\hline \multirow[t]{3}{*}{ Dissection videos } & SA/Agree & 27 & 35.7 & 33 & 61.1 & 60 & 53.1 & $\mathrm{X}^{\mathrm{l}}=9.944$ \\
\hline & Neutral & 29 & 49.2 & 20 & 37.0 & 49 & 43.3 & $\mathrm{MCP}=0.017^{*}$ \\
\hline & SDDisagree & 3 & 5.1 & 1 & 1.9 & 4 & 3.6 & \\
\hline Teaching methods that & idn't help in pre & aring fo & clinical s. & & & & & \\
\hline Models & SA/Agree & 3 & 5.1 & 6 & 11.1 & 9 & 8.0 & \\
\hline & Neutral & 10 & 16.9 & 7 & 13.0 & 17 & 15.0 & $\mathrm{X}^{2}=9.914$ \\
\hline & SD/Disagree & 46 & 78.0 & 41 & 75.9 & 87 & 77.0 & $\mathrm{MCP}=0.019^{*}$ \\
\hline Small Group activities & SA/Agree & 7 & 11.9 & 8 & 14.8 & 15 & 13.3 & \\
\hline & Neutral & 16 & 27.1 & 7 & 13.0 & 23 & 20.4 & $\mathrm{X}=8.854$ \\
\hline & SD Disagree & 36 & 61.0 & 39 & 72.2 & 75 & 66.3 & $\mathrm{P}=0.031^{*}$ \\
\hline Teaching methods that & idn't help in app & eciating & natomica & Ivariat & & & & \\
\hline Dissection videos & SAAgree & 12 & 20.3 & 2 & 3.7 & 14 & 12.4 & \\
\hline & Neutral & 22 & 37.3 & 18 & 33.4 & 40 & 35.4 & $\mathrm{X}^{\mathrm{Y}}=9.219$ \\
\hline & SD.Disagree & 25 & 42.4 & 34 & 62.9 & 59 & 52.2 & $\mathrm{P}=0.027^{*}$ \\
\hline Teaching methods that & elp in relating a & itomical & tructures & to the & thology & & & \\
\hline Dissection & SA/Agree & 41 & 69.5 & 47 & 87.0 & 88 & 77.8 & $\mathrm{X}^{2}=10.231$ \\
\hline & Neutral & 13 & 22.0 & 2 & 3.7 & 15 & 13.3 & $\mathrm{MCP}=0.039^{*}$ \\
\hline & SD-Disagree & 5 & 8.5 & 5 & 9.3 & 10 & 8.9 & \\
\hline Prosection & SA/Agree & 40 & 67.8 & 48 & 88.9 & 88 & 77.9 & $\mathrm{X}^{\prime}=11.901$ \\
\hline & Neutral & 16 & 27.1 & 2 & 3.7 & 18 & 15.9 & $\mathrm{MCP}=0.006^{*}$ \\
\hline & SD/Disagree & 3 & 5.1 & 4 & 7.4 & 7 & 6.2 & \\
\hline Models & SA/Agrec & 28 & 47.4 & 41 & 75.9 & 69 & 61.1 & $\mathrm{X}^{2}=10.209$ \\
\hline & Neutral & 24 & 40.7 & 9 & 16.7 & 33 & 29.2 & $\mathrm{P}=0.017 *$ \\
\hline & SDDisagree & 7 & 11.9 & 4 & 7.4 & 11 & 9.7 & \\
\hline Small Group activities & $\mathrm{SA} /$ Agrec & 22 & 37.3 & 36 & 66.7 & 58 & 51.3 & $\mathrm{X}^{2}=10.022$ \\
\hline & Neutral & 27 & 45.7 & 14 & 25.9 & 41 & 36.3 & $\mathrm{P}=0.018^{*}$ \\
\hline & SD/Disagree & 10 & 17.0 & 4 & 7.4 & 14 & 12.4 & \\
\hline Dissection videos & SA/Agree & 20 & 33.9 & 35 & 64.8 & 55 & 49.7 & $X^{2}=11.32$ \\
\hline & Neutral & 27 & 45.7 & 15 & 27.8 & 42 & 37.1 & $\mathrm{P}=0.010^{*}$ \\
\hline & SD/Disagree & 12 & 20.4 & 4 & 7.4 & 16 & 14.2 & \\
\hline Teaching methods that $l$ & Ip in understan & ing clini & 1 anaton & bette & & & & \\
\hline Dissection & SA/Agree & 55 & 88.1 & 51 & 94.4 & 103 & 91.1 & $\mathrm{X}^{2}=8.891$ \\
\hline & Neutral & 3 & 5.1 & 3 & 5.6 & 6 & 5.3 & McP $=0.021^{*}$ \\
\hline & SDDisagree & 4 & 6.8 & 0 & 0.0 & 4 & 3.6 & \\
\hline Lectures & SA/Agree & 53 & 88.1 & 51 & 94.4 & 40 & 91.1 & $\mathrm{X}^{2}=9.380$ \\
\hline & Neutral & 6 & 102 & 3 & 5.6 & 9 & 8.0 & McP $=0.013^{*}$ \\
\hline & SDDisagree & 1 & 1.7 & 0 & 0.0 & 1 & 0.9 & \\
\hline Models & SA/Agree & 50 & 85.7 & 49 & 90.7 & 99 & 87.6 & $\mathrm{X}^{2}=10.258$ \\
\hline & Neutral & 8 & 13.6 & 5 & 9.3 & 13 & 11.5 & scP $=0.009 *$ \\
\hline & SD/Disagree & 1 & 1.7 & 0 & 0.0 & 1 & 0.9 & \\
\hline Small Group activities & SA/Agrec & 32 & 54.2 & 41 & 75.9 & 73 & 64.6 & $\mathrm{X}^{2}=12.271$ \\
\hline & Neutral & 19 & 32.2 & 11 & 20.4 & 30 & 26.5 & ucP $=0.006^{*}$ \\
\hline & SD/Disagree & 8 & 13.6 & 2 & 3.7 & 10 & 8.9 & \\
\hline Teaching methods neith & rencouraged no & motivat & d learnin & & & & & \\
\hline Models & SA/Agree & 5 & 8.5 & 3 & 5.5 & 8 & 7.1 & \\
\hline & Neutral & 10 & 16.9 & 7 & 13.0 & 17 & 15.0 & $\mathrm{X}^{2}=11.191$ \\
\hline & SD/Disagree & 44 & 74.6 & 44 & 81.5 & ss & 77.9 & ucp $=0.009 *$ \\
\hline
\end{tabular}

X2: Chi-Square test ${ }^{\mathrm{MC}} \mathrm{P}$ : Monte Carlo corrected P-value *significant at $\mathrm{P} \leq 0.05 \quad$ SA: Strongly agree

SD: Strongly disagree

Results of the statistical analysis using Bonferroni Post Hoc test to observe differences between students with regards to their background, identified that UK students were more satisfied with teaching using models than the international students. This observed difference was statistically 
significant $(\mathrm{F}=3.491, \mathrm{P}=0.034)$. Results indicated a significant difference between local and international students and also between UK students and international students with regards to small group activities. Local students appreciated the activities of the small group more than international students while UK students appreciated the benefits of this small group activities more than international students $(\mathrm{F}=4.413, \mathrm{P}=0.014)$. The total score of satisfaction of students to all teaching methods combined showed a significant difference between UK students and international students $(\mathrm{F}=3.424, \mathrm{P}$ $=0.036$ ) because UK students have more appreciation $(84.6 \pm 6.6)$ to all teaching methods than international students $(76.9 \pm 10.9)$ (see Table $3)$.

Table 3. Relation between satisfaction scores, different teaching methods and students' background

\begin{tabular}{|c|c|c|c|c|c|c|}
\hline & Student status & & & Signif & & \\
\hline $\begin{array}{l}\text { 1eaching } \\
\text { Method }\end{array}$ & $\begin{array}{l}\text { Local } \\
(\mathrm{n}=72)\end{array}$ & $\begin{array}{l}\text { UK student } \\
(\mathrm{n}=15)\end{array}$ & $\begin{array}{l}\text { International } \\
(\mathrm{n}=26)\end{array}$ & $\mathbf{F}$ & $\mathbf{P}$ & $\begin{array}{l}\text { Bonferroni Post } \\
\text { Hoc test }\end{array}$ \\
\hline Dissection & $82.8 \pm 13.2$ & $88.0 \pm 7.8$ & $82.9 \pm 11.9$ & 1.137 & 0.325 & \\
\hline Prosection & $86.5 \pm 12.3$ & 88.777 .6 & $82.9 \pm 12.7$ & 1.344 & 0.265 & \\
\hline Lectures & $84.9 \pm 11.7$ & $88.5 \pm 6.9$ & $82.5 \pm 10.5$ & 1.448 & 0.239 & \\
\hline $\begin{array}{l}\text { Models } \\
\text { Small Group }\end{array}$ & $81.8 \pm 10.8$ & $85.7 \pm 9.8$ & $76.3 \pm 14.4$ & 3.491 & $0.034^{*}$ & $\mathrm{UK}, \mathrm{In}^{*}$ \\
\hline $\begin{array}{l}\text { Activities } \\
\text { Disection }\end{array}$ & $76.6 \pm 15.0$ & $81.0 \pm 12.1$ & $67.9 \pm 16.5$ & 4.413 & $0.014^{*}$ & L/nt* UK/nt" \\
\hline videos & $72.9 \pm 15.9$ & $5.5 \pm 11.4$ & $68.4 \pm 15.1$ & 1.247 & 0.291 & \\
\hline Total score & $80.9 \pm 9.3$ & $84.6 \pm 6.6$ & $76.9 \pm 10.9$ & 3.424 & $0.036^{*}$ & $\mathrm{UK} / \mathrm{nt}^{*}$ \\
\hline
\end{tabular}

L: Local students, UK: UK students, Int: International students, F: ANOVA test, *Significant at $\mathrm{P} \leq 0.05$

Students who had a previous Bachelor's Degree $(n=18)$, the mean score of satisfaction of some of these students who didn't study anatomy previously $(n=8)$ and had no previous dissection experience was higher $(93.1 \pm 7)$ than the remainder $(n=10)$ who studied anatomy previously (78 \pm 14.8$)$. This difference was statistically significant by Mann Whitney test $(\mathrm{Z}=2.327, \mathrm{P}=0.021)$.

Table 4. Satisfaction scores with regard to different teaching methods for male and female students

\begin{tabular}{|l|l|l|l|l|}
\hline \multirow{2}{*}{ Teaching method } & Gender of students & \multicolumn{3}{l|}{ Significance } \\
\cline { 2 - 5 } & Male $(\mathrm{n}=30)$ & Female $(\mathrm{n}=83)$ & \multicolumn{2}{|c|}{$\mathrm{P}$} \\
\hline Dissection & $86.3 \pm 12.3$ & $82.5 \pm 12.3$ & 1.460 & 0.147 \\
\hline Prosection & $86.4 \pm 13.9$ & $85.8 \pm 11.2$ & 0.237 & 0.813 \\
\hline Lectures & $82.4 \pm 14.2$ & $85.7 \pm 9.4$ & 1.183 & 0.244 \\
\hline Models & $79.3 \pm 14.7$ & $81.7 \pm 10.7$ & 0.943 & 0.421 \\
\hline Small Group activities & $74.8 \pm 17.9$ & $75.3 \pm 14.6$ & 0.176 & 0.861 \\
\hline Online dissection videos & $71.6 \pm 17.8$ & $72.4 \pm 14.4$ & 0.253 & 0.801 \\
\hline Total score & $80.1 \pm 11.7$ & $80.6 \pm 8.8$ & 0.221 & 0.826 \\
\hline
\end{tabular}

t: Student t-test

*significant at $\mathrm{P} \leq 0.05$
Results of the comparison of scores of satisfactions of different teaching approaches with students' gender demonstrated that there was no significant difference between the two sexes (Table 4). Scores of satisfactions for dissection and prosection were approximately equal in males but higher than those of females for these two teaching approaches. On the other hand, for lectures, models, small group activities and online videos it was higher in females. These differences were statistically insignificant $(\mathrm{p} \leq 0.05)$ (see Table 4).

\section{Discussion}

This study addressed the perception of students to different teaching methods. During the academic year (2016/17), dental students' performance in class tests was very strong. Their performance in head and neck class test was slightly higher than their performance in any other class tests. Dissection was only performed while teaching head and neck region. That confirmed the positive impact of this teaching method.

It was observed in this study that no singular approach fulfilled all the teaching objectives. This study confirmed that a multimodal approach to teaching is the best due to several factors. The main factor was the diversity of students' background that has led to variability amongst students in terms of their educational background and thus, their learning styles. This finding coincided with the findings of Chinnah et al. [4] who stated that students benefit more from a multimodal delivery, which emphasizes acquiring applicable skills and knowledge over factual recall. These different methods of teaching help in providing autonomous supportive environment.

The findings of this study demonstrated that 2 nd year students appreciated more dissection and small group activities as teaching methods that provide a good background for other Basic Sciences subjects than 1 st year students. These differences were statistically significant. It was obvious that 2 nd year students who were more academically mature, had better overview on how anatomy is fundamental and fits in other discipline areas.

\subsection{Teaching methods}

The same findings were observed with regards to small group activities and dissection videos as teaching methods that provide a good background for clinical disciplines. Previous studies noted that dental students are aware of the relevance of anatomy teaching to their future profession [5]. 2nd year students had also more appreciation for small group activities than 1st year students as they strongly disagreed/disagreed that small group activities didn't help to prepare them for clinical skills. This 
difference was statistically significant. 2nd year students had a better understanding to the importance of small group activities in preparing them better for the next clinical stage. This finding was parallel to that of [4] who found that working as part of a team allows students to understand what it is like to work in a clinical multidisciplinary team. In comparison to 1 st year students, data collected about the importance of different teaching methods in relating anatomical structures to pathology and in understanding clinical anatomy showed that 2nd year students had also more appreciation to almost all teaching methods, excluding only the online dissection videos. These differences were statistically significant (see Table 2).

\subsection{Prosection}

Students found prosection to be more accessible with the emphasis on it being more explicit compared to dissection that needs more time and effort. It received the highest satisfaction score by most dental students as a useful teaching method followed by lectures then dissection. This high rating for prosection could be explained by the presence of clinical demonstrators during the practical sessions who relate the subject to clinical cases and make the subject more interesting. A slight difference in opinion was noted by Patel and Moxham [3] who interviewed lecturers; found that the majority (69\%) selected dissection, followed by prosections as the most appropriate teaching tools.

The only difference noticed in this research was that international students appreciated both dissection and prosection equally as their scores of satisfactions for both was the same (82.9) (see Table 3 ). International students who seek a better range of learning opportunity abroad to enhance their future skills, had more consideration for dissection in comparison to local and UK students.

In this study, it was found that more female students would work on prosected specimens rather than perform actual dissection (see Table 3). This finding in itself is alarming in the sense that we are dealing with a generation who are more exam oriented. They are not interested in enriching dissection/surgical skills which is the basic skill they will rely on in future if they decide to be maxillofacial or oral surgeons.

\subsection{Prosection versus Dissection}

It is well known that learning using dissection has advantages that are not easy to quantify such as preparing students for clinical practice, practicing manual skills and understanding the relationship between patients' symptoms and pathology [4]. No one can deny that cadaver dissection is a key factor in the process of producing future surgeons. Hence, the importance of these anatomy dissection courses for learners to achieve proper anatomical knowledge. Unlike prosection, where prediction can dominate, dissections can provide a sense of surprise at the identification of anatomical variations. That was in line with the findings of this study with regards to students' perception in relating different teaching methods to anatomical variations (see Table 1). However, it was concluded that dissection courses were viewed by both lecturers and students as most "fit for purpose" in meeting learning outcomes, but no single teaching tool met all aspects of the curriculum. This finding is in consistent with the findings of the present research. On the other hand, cost effectiveness and time factor strongly debated whether full cadaver dissection is still suitable for modern undergraduate education or not. Prosections offer a number of advantages; prosection-based courses are flexible, contextual and time-efficient as structures and their relations are easily observed. Fewer cadavers are needed as more than one student cohort can use the prosections [6]. Despite these advantages, preparation of prosected specimens is time-consuming and requires ample skilled personnel to create multiple prosections of each body region. A previous report showed no significant differences in outcomes between students learning anatomy from dissection and those learning it by examining prosected cadavers [7].

Although students' initial encounter with cadaver may induce anxiety and emotions, results of a study conducted by Dosani and Neuberger 8 demonstrated that the dissection experience is very beneficial to students but it is not the only effective teaching method. In the current study, the analysis of gender differences showed that the score of satisfaction regarding the dissection experience was higher in males $(86.3 \pm 12.3)$ than females $(82.5 \pm 12.3)$. That is because some females struggle with coping with the stressors of anatomy dissection. On the contrast, another study conducted by Akpan and Andre [9] found no gender differences in the impact of dissection but only because they used simulation before dissection.

\subsection{Gender Differences}

Gender differences have been found most frequently in the degree of anxiety, the mode of coping and adapting to the cadaver experience. Higher stress was reported by female students following initial exposure to dissection [10]. However, the dissecting room experience should have a positive impact on the clinical attitudes of students, i.e. they should become capable of integrating the negative emotions caused by the experience by becoming aware of them then developing effective strategies to deal with them. Successful coping is regarded as the ability to handle 
emotions and behavior connected to the situation [11].

In the current research, it was noticed that although the total number of male students was only $26.45 \%$, their satisfaction score for dissection was higher $(86.3 \pm 12.3)$ than that of their female classmates $(82.5 \% \pm 12.3)$ although statistically insignificant (see Table 4). Dissection is usually preferred by dental students who ultimately wish to develop their surgical skills to be either maxillofacial or oral surgeons in the future. Female dental students would not necessarily choose to be surgeons in their future careers in contrast to males who have more tendencies toward enhancing their surgical skills through dissection. Online dissection videos had the smallest satisfaction score for males and females as it is the least interactive method of teaching compared to other teaching approaches used in this study (see Table 4).

The present study revealed a positive correlation between previous study of anatomy and the score of satisfaction with regards to dissection. Students who had no previous experience with dissection were more interested in dissection. This observed difference was statistically significant (Mann Whitney=2.327, $\mathrm{P}=0.021$ ). This outcome was most probably attributed to the excitement by a new experience. This result is consistent with the findings of the study by Larkin and McAndrew [11] who reported that previous dissection experience was a reason for students not to participate in a voluntary dissection course.

\subsection{Small Group Teaching}

The small group activities that were organized in this research allowed students to participate in the discussion of clinical relevant information, in solving some clinical scenarios, in identifying anatomical structures, in drawing and labeling diagrams, and in carrying out different dissection activities. All these different types of activities helped in supporting the autonomous environment. The score of satisfaction of students to small group activities in this study were 74.8 and 75.3 for male and female students respectively. Kusurkar and Croiset [12] mentioned that small group activities are viewed to support autonomy in medical education. Burgess and Ramsey-Stewart 3 found that small group activities promote collegiality and sense of belonging (relatedness) because students develop the sense of being connected to each other with the same goal.

\subsection{Lectures}

Bengtsson et al. [14] noted that dedicated lectures with good choices of learning materials, discussions and good assessment methods, enhance enthusiasm and student learning. This is consistent with the findings of this research where it was found that students have chosen lectures to be the best teaching method that prepared them for clinical skills and was the best in relating anatomical structures to pathology (see Table 1). Although lecture material was not rated highly in terms of engaging students, it was found to be very useful in terms of achieving success. It appears that, in spite of efforts to modernize the course and place greater emphasis on active learning, students still perceive didactic teaching as essential to achieve learning objectives 4 .

\subsection{Plastic Models}

In the current study, the use of plastic models (PMs) was well received by students. The score of satisfaction for this approach was 79.3 and 81.7 for male and female students respectively. Students do believe that plastic models are a useful supplement to learning. Students' support for the use of models may reflect their belief that studying anatomical knowledge by a three-dimensional representation is more relevant to their degree.

Oh et al. 5 stated that such models are even more helpful than 3DVT models in cases of complicated cross-sectional anatomy. Generally speaking, educational methods have moved towards a studentcentred orientation, the self-directed learning. With recent advances in technology, reduction in teaching time and increase in class size had made the online dissection videos increasingly used to foster student learning 16. Evidence shows that learning anatomy using online or computer based [17] dissection resources can enhance self-directed learning by supplementing other more traditional teaching methods.

\section{Educational Implications of the Study}

The results of this study provide useful information in selecting effective anatomy teaching methods and generating educational tactics/strategies. Learner's analysis is an important step in identifying the general level of the learner characteristics. The latter include gender differences, background information and previous anatomy knowledge. This study gives guidance towards generation of teaching objectives and selection of appropriate strategies to achieve these objectives. Lecturers should sustain a good level of students' attention by using different teaching approaches. Furthermore, it is important to explain the multimodal teaching to students in order to emphasize the value of learning through a variety of teaching tools. 


\section{Limitations of the Study}

While the results of this study have shed some light on students' perceptions about teaching anatomy, further steps must be done to uncover some of the factors that influence these perceptions. To enhance students 'academic success, some future recommendations can be put in place:

1. Preparing and implementing curriculum and teaching interventions aiming at introducing a more student-centred environment in the anatomy classroom

2. This study only included a section of students that studied anatomy as a foundation course for dentistry. This limited scope does not take into account other requirements and learning styles for a large number of students who study anatomy outside the dental curriculum as medical, nursing, Allied Health Sciences nursing or physiotherapy students. Educators must be aware of choosing the most suitable active learning approaches that meet the objectives of their own courses

3. Take into consideration other methodologies such as virtual reality dissection and living anatomy sessions

4. The present approach seems worth pursuing further by obtaining some student quotes and ideas from focus groups, discussing the effect of different teaching approaches on their learning and performance in exams. These ideas will be an important platform to make some headway into resolving any differences that may be present between students' and the professional bodies.

5. It would be beneficial to have instructors focusing on teaching approaches that promote deeper ideas of learning in order to help shape students' views of learning anatomy and help to advance the educational environment.

\section{Conclusions and Recommendations}

The use of a multimodal paradigm in teaching anatomy has received support from many anatomists [18]. There has never been any doubt about the importance of using different teaching approaches and its huge influence on learning. Lecturers should explain the rationale behind the use of different teaching methods, as adult learners tend to engage more readily when objectives and relevance are clear. This would be a positive step in moving the learning environment to match the goal for a more modern anatomy education experience.

These different teaching approaches have a great impact on students' learning. It facilitates internal motivation by supporting autonomy, competence and relatedness, the major elements of self-determination theory. Students appear to profit most when diverse and system-based modalities are integrated [19].
The results of this study enlighten the path while selecting appropriate strategies for different teaching objectives. Because acquiring anatomical skills is essential to perform safe surgical procedures, full body dissection best fits medical students particularly those with surgical career intentions. Some schools have neither the money nor time in the curriculum to support dissection labs. Therefore, plastination / prosection seems the best fit for nurse and allied health science students as the principle teaching method to substitute for dissection. Dental students would benefit from only dissecting the head and neck region as they can use prosected specimens for studying the rest of the body.

\section{References}

[1] Adib-Hajbaghery, M., Aghajani, M., (2011). Traditional Lectures, Socratic Method and Student Lectures: Which One do the Students Prefer? Webmed Central Medical Education. 2: WMC001746.

[2] Dieter, J., Salme, L., Randy, M., Orla, N., (2006). Students' Perceptions of effective classroom and clinical teaching in dental and dental hygiene education. J Dent Educ.; 70: 624-635.

[3] Patel, K., Moxham, B., (2006). Attitudes of professional anatomists to curricular change Clin. Anat., 19 (2) pp. 132-141.

[4] Chinnah, T., De Bere, S., Collet, T., (2011). Students' views on the impact of peer physical examination and palpation as a pedagogic tool for teaching and learning living human anatomy. Medical Teacher 33(1): e27-36.

[5] Dyer, G.S., Thorndike, M.E., (2000). Quidne mortui vivos docent? The evolving purpose of human dissection in medical education. Acad Med 75:969-979.

[6] Azer, S. A., Eizenberg, N., (2007). Do we need dissection in an integrated problem-based learning medical course? Perceptions of first- and second-year students. Surg. Radiol. Anat., 29 (2) pp. 173-180.

[7] Yeager, V. L., (1996), Learning gross anatomy: Dissection and prosection. Clin. Anat., 9: 57-59.

[8] Dosani, F, Neuberger L., (2016) Anatomy and humanity: Examining the effects of a short documentary film and first anatomy laboratory experience on medical students. Anat Sci Educ 9:28-39.

[9] Akpan, J., Andre T., (2000). Using a computer simulation before dissection to help students learn anatomy. J Comput Math Sci Teach 19:297-313.

[10] Sándor, I., Birkás, E., Győrffy, Z., (2015). The effects of dissection-room experiences and related coping strategies among Hungarian medical students. BMC Med Educ. 15:73. 
[11] Larkin T., McAndrew, D., (2013). Factors influencing students' decisions to participate in a short "dissection experience" within a systemic anatomy course. Anat Sci Educ 6:225-231.

[12] Kusurkar R., Croiset G., (2015). Autonomy support for autonomous motivation in medical education. Med Educ Online 20:27951.

[13] Burgess, A., Ramsey-Stewart, G., (2014). What motivates surgeons to teach dissection anatomy to medical students and surgical trainees? Adv in Med Educ and Practice, 2015:6, 11-16.

[14] Bengtsson M., Ohlsson B., (2010). The nursing and medical students' motivation to attain knowledge. Nurse Educ Today 30:150-156.

[15] Oh, C. S., Kim, J. Y. and Choe, Y.H., (2009). Learning of cross-sectional anatomy using clay models. Anatomical Sciences Education, 2, 156-159.

[16] Khot, Z., Quinlan K., Norman G., Wainman B., (2013). The relative effectiveness of computer-based and traditional resources for education in anatomy. Anat Sci Educ. 6(4):211-5. doi: 10.1002/ase.1355. Epub 2013 Mar 18.

[17] Tam, A.R., Hart, S.M., Williams, R., Holland, D., Heylings and Leinster, S., (2010). Evaluation of a computer program ('disect') to consolidate anatomy knowledge: A randomised-controlled trial Pages e138e142 | Published online: 10 Mar.

[18] Rizzolo, L. J., Rando, W. C., O'Brien, M. K., Haims, A. H., Abrahams, J. J. and Stewart, W. B., (2010), Design, implementation, and evaluation of an innovative anatomy course. Anat Sci Educ 3, 109-120.

[19] Estai, M., Bunt, S., (2016). Best teaching practices in anatomy education: A critical review. Annals of Anatomy, 208, 151-157. 